\title{
CONCEPÇÕES DE LAZER SOB A PERSPECTIVA DOS ADULTOS
}

Recebido em: 02/11/2018

Aceito em: 12/09/2019

\author{
Iara Falleiros Braga ${ }^{1}$ \\ Andrêza Roberta Bezerra dos Santos ${ }^{2}$ \\ Universidade Federal da Paraíba (UFPB) \\ João Pessoa - PB - Brasil
}

RESUMO: Esse estudo teve o objetivo de analisar as concepções de lazer sob a perspectiva dos adultos. Foi adotada uma abordagem qualitativa, realizada através de um questionário aberto online na plataforma Google Forms, por meio da técnica metodológica snowball. Os sujeitos que compuseram a pesquisa foram 21 adultos, na faixa etária dos 25 aos 38 anos. A análise dos dados pautou-se na modalidade de análise hermenêutica-dialética. Foram identificados 3 núcleos de sentidos que possibilitaram compreender a concepção do lazer para os adultos: compreensão de lazer: "tempo e atitude", a idade e atividades consideradas como lazer, e "produtos" de lazer. Os resultados mostraram a associação entre lazer e satisfação pessoal/descanso, e o paradoxo entre lazer e trabalho, com mudanças na percepção dos sujeitos mais notórias nas faixas etárias dos 25 aos 29 anos e dos 30 aos 38 anos.

PALAVRAS CHAVE: Adulto. Atividades de Lazer. Cultura.

\section{ADULT'S PERSPECTIVE ON RECREATION}

ABSTRACT: This study aimed to analyze the recreation conceptions on adults' opinion. The type of approach used was the qualitative approach, trough an open online questionnaire on Google Forms platform, using the snowball sampling technique. The individuals that participated in the research were twenty one adults, in the 25-38 age group. The data analysis was based on the hermeneutic dynamic method of analysis. Three nucleus were identified that allows to understand the conception of recreation for adults: comprehension of recreation: time and behavior, the age, activities considered as recreation and recreation "products". The results showed that people often associate recreation and personal satisfaction/repose, and the paradox between recreation and work, with changes of the individual's perception been more considerable between the 25-29 age group and the 30-38 age group.

\footnotetext{
${ }^{1}$ Graduada em Terapia Ocupacional pela Universidade Federal de São Carlos (2008). Mestre em Ciências pelo Programa de Pós Graduação Enfermagem em Saúde Pública, EERP/USP (2012). Doutora em Ciências pelo Programa de Pós Graduação Enfermagem em Saúde Pública (2017). Atualmente é professora adjunta do Departamento de Terapia Ocupacional da Universidade Federal da Paraíba (UFPB). ${ }^{2}$ Graduada em Terapia Ocupacional pela Universidade Federal da Paraíba (2018). Residente no Programa de Residência Integrada Multiprofissional em Saúde Hospitalar - RIMUSH com Ênfase em Atenção à Saúde do Paciente Crítico no Hospital Universitário Lauro Wanderley - HULW/UFPB.
} 
KEYWORDS: Adult. Leisure Activities. Culture.

\section{Introdução}

O processo de desenvolvimento se dá através das transformações que ocorrem ao longo da vida do sujeito e que estão imbricadas a um conjunto complexo de fatores tais como, socioeconômicos, culturais, étnicos/raciais, de gênero, dentre outros (OLIVEIRA, 2004b). A adultez é uma das etapas dos estágios de desenvolvimento humano. Esses estágios constituem uma forma de organização de acordo com o que é esperado historicamente e culturalmente para cada fase da vida, mas que vai se diferenciar, considerando as singularidades e coletividades dos sujeitos. (ARAÚJO, 2008)

Palacios (1995) sintetiza três fatores que se relacionam aos processos de transformações, ou de desenvolvimento: “1) a etapa da vida em que a pessoa se encontra; 2) as circunstâncias culturais, históricas e sociais nas quais sua existência transcorre e 3) experiências particulares privadas de cada um e não generalizáveis a outras pessoas" (1995, p. 9).

É comum encontrar na literatura o desenvolvimento humano sendo descrito apenas pelo viés maturacional biológico, de modo que as transformações acabam sendo generalizadas e apontadas como se ocorressem para todos os seres humanos de forma similar. No entanto, as transformações do desenvolvimento não podem ser representadas em sua totalidade pelos fenômenos biológicos, pois as mudanças mais relevantes se atêm às circunstâncias sociais e histórico-culturais e às peculiaridades das experiências de cada sujeito (ARAÚJO, 2008). 
A fase adulta é retratada, geralmente, como fase "aproblemática", destacada como ápice da maturidade, o que resulta em uma impressão de estabilidade, já que as transformações biológicas mais evidentes ficaram na fase da adolescência. Assim, é esperado que, nos demais contextos da vida (gerenciamento de suas escolhas pessoais, profissionais, sociais), o sujeito esteja estabelecido solidamente (BOUTINET, 2000).

No entanto, essa concepção de estabilidade e ausência de mudanças relacionadas à adultez contradiz a ideia de desenvolvimento humano de transformação, bem como às transformações socioeconômicas de determinado local. Levinson (1977) afirma que a vida adulta é marcada por transições e transformações, essas ocorrem levando em consideração à forma como o sujeito adulto enxerga a si próprio, ao mundo e aos outros, relacionando diretamente tudo isso aos papeis assumidos durante essa fase, sobretudo às expectativas sociais acerca deles.

Compreender a vida adulta, de forma geral, pode muitas vezes nos levar a uma normatização do que é ser adulto, pelo fato de considerar não somente a faixa etária, mas também características comuns nesta etapa do desenvolvimento. Contudo, vale ressaltar que há diversas formas de "ser adulto", de modo que, visto que ele é profundamente marcado pelo contexto cultural contemporâneo de cada sociedade (CARNEIRO; SAMPAIO, 2015).

Assim, a forma como cada indivíduo vivencia essa etapa da vida será atravessada pelas questões de classe social, etnia, gênero, religião, e cultura de um modo amplo. Até mesmo atividades comumentes exercidas por sujeitos de qualquer lugar do planeta, como por exemplo, o autocuidado, podem ser experienciadas de maneiras distintas por quem as vivencia, pois, a interpretação delas varia de acordo com 
as visões de mundo e a significação atribuída por cada cultura (CARNEIRO; SAMPAIO, 2015; BARROS; ALMEIDA; VECCHIA, 2007).

Mosquera; Stobaus (1982, p.98) relata "que cada fase tem uma problemática específica, dividida em sub-problemáticas que atingem as pessoas em seus momentos decisivos ante seu próprio projeto vital e suas relações com os outros". Ele apresenta as fases da vida adulta em adultez jovem, adultez média e adultez velha, e, dentro delas, divide subcategorias cronológicas.

Essas subcategorias subdividem-se em: adultez jovem inicial, que contempla os indivíduos de 20 a 25 anos; adultez jovem plena, que vai desde os 25 aos 35 anos; adultez jovem final que abrange dos 35 aos 40 anos; a adultez média inicial, dos 40 aos 50 anos; a adultez média plena, dos 50 aos 60 anos; adultez média final dos 60 aos 65 anos; a adultez velha final, dos 65 aos 70 anos; adultez velha plena; dos 70 aos 75; adultez velha final, que vai dos 75 até a morte (MOSQUERA; STOBAUS, 1982).

Santos e Antunes (2007) ressaltam que:

A questão cronológica, que divide cada fase na vida adulta parece estar ligada à época em que a sociedade vivencia historicamente até a contemporaneidade, ou seja, as divisões de faixa etária podem ser distribuídas de acordo com o contexto social em que a pessoa estiver inserida (p.152).

A adultez não é linear, de modo que não ocorre de forma sequencial seu desenvolvimento. Desta forma, ela é descrita baseada em modelos de confluência, que descrevem em linhas gerais o que o sujeito adulto vivencia em cada etapa da adultez, levando em consideração fatores sociais e individuais (idiossincráticos) (MENDONÇA, 2007).

As subfases contempladas neste estudo são descritas como: a adultez jovem plena, etapa em que o "adulto toma consciência da chegada em sua existencialidade adulta e procura se dar significância pessoal"; e na adultez jovem final, na qual "o 
indivíduo vivencia situações que lhe atribuem o verdadeiro valor de sua existência e compreende, ou pelo menos idealiza, o que constituirá sua realização.” (SANTOS; ANTUNES, 2007, p.153).

O estilo de vida adotado por tais indivíduos está relacionado com as decisões tomadas acerca das escolhas de suas relações afetivas e profissionais, seus consumos, e as esferas sociais que o privilegiam. São esses que moldam a identidade do sujeito, seja ela pessoal ou social. A partir disso, é comum a esses indivíduos criarem hábitos e rotinas que o identificam como seres adultos (SOUSA, 2010).

$\mathrm{Na}$ sociedade pós-moderna em que nos inserimos, é comum os adultos vivenciarem uma rotina marcada por um ritmo bastante acelerado, com várias atividades sendo executadas simultaneamente. Também são muitos os papeis sociais vivenciados durante essa fase - casamento, paternidade ou maternidade, trabalho, graduação, divórcio, pós-graduação, viuvez, dentre outros - que são transformados ao longo do tempo e que influenciam diretamente na realização de atividades do cotidiano. (MOURA,1999) As atividades cotidianas humanas "advêm da necessidade de produzir, realizar e fazer, porém também demandam satisfação, prazer” (MARTINELLI, 2011, p.112).

No entanto, devido às obrigações implicadas pelos papeis sociais assumidos, muitas vezes as atividades cotidianas são executadas automaticamente, de forma mecânica, sem que saibamos ao certo o porquê de as estar realizando. Do mesmo modo, atividades significativas e prazerosas são banalizadas se não forem enxergadas como uma obrigação (MARTINELLI, 2011).

Por outro lado, há um grande estigma acerca da vivência do ócio, bem como a livre escolha de atividades durante esse tempo, já que a rotina imposta, no sistema 
capitalista, demanda produção. Esta, por conseguinte, deve ser constante, pois quando não se produz, mesmo que por um curto período de tempo, é considerado improdutivo, o que acaba gerando uma sensação de inutilidade por parte daqueles que se permitem tal prazer (NASCIMENTO, 2017).

Hoje, mais que nunca, a produtividade através do trabalho tem se arraigado em todas as esferas da vida dos seres humanos, de modo que, a cada dia destinamos mais horas do nosso tempo livre em função deste, que é uma obrigação. O que podemos apontar como uma das causas da invasão do trabalho no tempo destinado ao lazer é o resultado da combinação de um sistema capitalista e um mundo globalizado, que através do uso contínuo da internet, faz com que o ambiente de trabalho se amplie cada vez mais, chegando à casa, ao transporte, e até mesmo ao lazer destes indivíduos (BARCELOS, 2009).

As possibilidades de vivência do componente lúdico da cultura na vida adulta são restritas, principalmente pela falta de tempo para se dedicar a essa manifestação e pela lógica do sistema capitalista que afasta o adulto do lúdico por valorizar exacerbadamente a produção no tempo de trabalho. Muitas vezes, as pessoas têm o tempo liberado das obrigações, porém não sabem o que fazer durante esse tempo, pois lhes falta "educação" para tal. O sistema anula as outras dimensões de expressão das pessoas, pois enxerga o trabalho como principal ocupação. Em alguns casos, só valoriza o lazer quando suas atividades se voltam para o entretenimento no viés do consumo (ALVES; MARCELLINO, 2008, p. 4).

Historicamente há uma relação dialética entre trabalho e lazer, pois foi a partir da Revolução Industrial, e do advento das lutas trabalhistas, que emergiu o então fenômeno do lazer. Com a diminuição da carga horária de trabalho formal, dos dias de folga e das férias, surgiu a necessidade de ocupar o tempo ocioso desses trabalhadores (GOMES, 2004). 
Assim, Dumazedier (2001), expõe que a necessidade de lazer está diretamente ligada à industrialização e à urbanização. Portanto, o lazer deixou de ser um privilégio apenas da burguesia, com a liberação periódica de tempo, e garantiu acesso também ao proletariado. Com o tempo livre das obrigações profissionais, familiares e sociais, os indivíduos poderiam vivenciar um conjunto de ocupações voltadas para o descanso, divertimento ou desenvolvimento da personalidade. Por isso, o autor entende ser o lazer um fenômeno moderno, cuja necessidade se acentua nas sociedades industrializadas (GOMES, 2004).

Foi Dumazedier (1979) que apresentou uma visão diferente para o que era até então difundido. A partir das pesquisas empíricas realizadas na França, ele escreveu sobre as dimensões reais do lazer e sua relação com a dinâmica das mudanças culturais, sociais e do mundo do trabalho, em seu livro "A sociologia empírica do Lazer”. O autor também atribuiu aspectos específicos e constituintes do lazer: aspecto pessoal (descanso, divertimento e desenvolvimento da personalidade); aspecto desinteressado (sem fins lucrativo, ideológico, material etc.); aspecto hedonístico (busca do estado de satisfação); aspecto liberatório (sem obrigações institucionais, familiares, religiosas, profissionais, políticas etc.).

Nessa perspectiva, para definir "lazer", Marcellino (1987) leva em consideração dois aspectos-chave: a atitude e o tempo. Assim, a atividade precisa gerar satisfação e ser uma prática vivenciada no tempo livre das obrigações cotidianas dentre outras, trabalho, educação e família - que proporcionem também desenvolvimento pessoal e social. Martinelli (2011) complementa afirmando que "as atividades de lazer se constituem como possibilidades de realização pessoal, uma vez que dependem da própria escolha e interesse individuais" (p.113). 
O lazer se inter-relaciona com as outras esferas da sociedade (relações sociais, econômicas, artísticas, políticas, culturais), levando em consideração a teoria da ação comunicativa, o lazer expressa três mundos: social (relação entre as pessoas); objetivo (transformação da natureza) e pessoal (construção da subjetividade) (ALMEIDA; GUTIERREZ, 2011).

Em consonância, ainda existem os fatores que influenciam na prática do lazer e nas possibilidades da vivência deste, sendo consideradas por Marcellino (2007) como, barreiras intraclasses sociais — entre outros, gênero e faixa etária - e interclasses sociais - fator econômico, ou seja, a classe social que o indivíduo se insere. De acordo com este autor, esses fatores vão possibilitar diferentes oportunidades de acesso e práticas de lazer.

No Brasil, temos formas variadas de viver o lazer, especialmente quando, para muitos, o lazer é ainda uma luta por direito de cidadania. Embora seja um direito social garantido pela Constituição Federal, que, em seu Art. 6 diz: "são direitos sociais a educação, a saúde, o trabalho, a moradia, o lazer, a segurança, a previdência social, a proteção à maternidade e à infância, a assistência aos desamparados, na forma desta constituição" (BRASIL, 1988, grifo nosso), o lazer é esquecido e desvalorizado perante os demais direitos, tidos de maior importância, dignos de maior investimento pelo poder público (LOPES, 2017).

As políticas públicas de lazer além de terem pouco investimento por parte da gestão, quando este investimento ocorre acaba por não abarcar as diferentes áreas do lazer, que segundo Marcellino (2006), são seis áreas fundamentais: os interesses artísticos, os intelectuais, os físicos, os manuais, os turísticos e os sociais. 
Levando em consideração os aspectos descritos acima, a respeito da fase adulta e do lazer, ambos podendo ser influenciados por diversos fatores - pessoais, econômicos, históricos, culturais, políticos e sociais -, objetiva-se compreender nesta pesquisa as concepções que os adultos têm acerca do lazer, as possíveis mudanças na vivência do lazer que ocorrem ao longo do desenvolvimento e os fatores que influenciam no significado do lazer para os adultos. Partimos do pressuposto de que as concepções de lazer são diversas e se transformam de acordo com a faixa etária, com as diferenças socioeconômicas e culturais.

\section{Metodologia}

\section{Tipo de Estudo}

Trata-se de uma investigação com abordagem qualitativa, pois ela proporciona “aprofundar-se no mundo dos significados das ações e relações humanas, um lado não perceptível e não captável em equações, médias e estatísticas” (MINAYO, 2001, p.22).

\section{Participantes}

Os sujeitos que compuseram a pesquisa foram adultos de 25 a 35 anos (adulto jovem pleno) e de 35 a 40 anos (adulto jovem final) embasados na subdivisão das etapas da vida adulta apresentada por Mosquera; Stobaus (1982). Foram adotados como critérios de inclusão ter idade entre 25 e 40 anos, independente do sexo; e concordar com os termos pré-estabelecidos no Termo de Consentimento Livre e Esclarecido. Enquanto os critérios de exclusão se caracterizam por não concordar com os termos da pesquisa, não preencher completamente o questionário; não se enquadrar na faixa etária determinada para o estudo; e não ter acesso a internet para responder ao questionário na 
plataforma Google Forms.

\title{
Instrumentos para Coleta de Dados
}

Foi utilizado como instrumento para coleta de dados, um questionário aberto, que foi realizado online, na plataforma Google Forms, que foi disponibilizado através de um endereço eletrônico e, quando preenchido pelos respondentes, mostraram imediatamente as respostas na página do Google Forms da pesquisadora, mantendo os questionários em sigilo.

Para o recrutamento dos participantes, foi utilizada a técnica metodológica snowball, também chamada snowball sampling (BIERNACKI; WALDORF, 1981). Essa técnica é conhecida no Brasil como "Bola de Neve" ou, ainda, como "cadeia de informantes" (ALBUQUERQUE, 2009). A abordagem através dessa técnica foi baseada nos princípios descritos por Vinuto (2014):

\begin{abstract}
A execução da amostragem em bola de neve se constrói da seguinte maneira: para o pontapé inicial, lança-se mão de documentos e/ou informantes-chaves, nomeados como sementes, a fim de localizar algumas pessoas com o perfil necessário para a pesquisa, dentro da população geral. Isso acontece porque uma amostra probabilística inicial é impossível ou impraticável, e assim as sementes ajudam o pesquisador a iniciar seus contatos e a tatear o grupo a ser pesquisado. Em seguida, solicita-se que as pessoas indicadas pelas sementes indiquem novos contatos com as características desejadas, a partir de sua própria rede pessoal, e assim sucessivamente e, dessa forma, o quadro de amostragem pode crescer a cada entrevista, caso seja do interesse do pesquisador. Eventualmente o quadro de amostragem torna-se saturado, ou seja, não há novos nomes oferecidos ou os nomes encontrados não trazem informações novas ao quadro de análise (p. 203).
\end{abstract}

A partir da delimitação do público da pesquisa, foi feito um mapeamento da lista de contato das pesquisadoras, de modo a fazer um levantamento dos contatos que se adequavam aos critérios de inclusão da pesquisa. A partir disso, foram selecionadas 
duas sementes, ou informantes iniciais, que dariam início ao estudo. Foi feito o contato com estas através de um aplicativo de mensagem instantânea, whatsapp, e explicado o objetivo da pesquisa e perguntado se elas poderiam contribuir respondendo o questionário, e indicando, no final deste, o contato de um pessoa do seu círculo social, que também se incluísse no público alvo da pesquisa. Posteriormente, após a indicação, os novos contatos foram convidados a participar do estudo através do aplicativo whatsapp ou via email, explicitando o objetivo do estudo, e que ao final deveriam indicar um novo contato para o estudo.

A coleta foi encerrada a partir da não indicação de novos nomes pelos participantes, e, pelos sujeitos indicados não responderem ao questionário. Finalizando a pesquisa com participação de 23 sujeitos que responderam o questionário na plataforma, sendo destes 2 excluídos dos resultados por não se adequar aos critérios de inclusão, um participante não se enquadrava na faixa etária pré determinada, e outro não respondeu por completo o questionário, critério este que se aplicava como critério de exclusão.

\section{Análise dos Dados}

Os dados coletados através da aplicação do questionário foram analisados utilizando a modalidade de análise hermenêutica-dialética. A hermenêutica parte da ideia da interpretação, ou seja, metodologicamente falando, compreensão dos sujeitos, seus fatos e relatos. Já a dialética parte do pressuposto da contradição e contraposição da ideia, do diálogo, da pergunta, e "busca nos fatos, na linguagem, nos símbolos e na cultura, os núcleos obscuros e contraditórios para realizar uma crítica sobre eles" (ALENCAR; NASCIMENTO; ALENCAR, 2012, p.244). 
Quando esses elementos são harmonizados, concebem o que Minayo (1992) descreve no método hermenêutico-dialético "a fala dos atores sociais é situada em seu contexto para melhor ser compreendida. Essa compreensão tem, como ponto de partida, o interior da fala. E, como ponto de chegada, o campo da especificidade histórica e totalizante que produz a fala" (p.77).

Esse método é estruturado pelos seguintes passos para a análise dos dados: Nível das determinações fundamentais; Nível do encontro com os fatos empíricos; Ordenação dos dados; Classificação dos dados; Análise final. (ALENCAR; NASCIMENTO; ALENCAR, 2012) De modo a relacionar-se com o tema, a metodologia foi escolhida por conseguir uma interpretação aproximada da experiência do sujeito com o mundo, com a história, a sociedade, a cultura, contribuindo assim para a análise das concepções de lazer sob a perspectiva das pessoas adultas e as implicações de ordem histórica, sociocultural, política, econômica, que estão envolvidas na vida do sujeito analisado e que se relacionam direta e indiretamente com as atividades de lazer.

\section{Aspectos Éticos}

Por envolver seres humanos, este estudo foi submetido e aprovado pelo Comitê de Ética em Pesquisa em Seres Humanos (CEP) do Centro de Ciências Médicas (CCS), da Universidade Federal da Paraíba (UFPB), fundamentado conforme as diretrizes da Resolução 466/2012 do Conselho Nacional de Saúde, sob o parecer consubstanciado número 2.720 .836 .

Os participantes da pesquisa foram apresentados aos objetivos, riscos e benefícios antes de responder ao questionário através do termo de consentimento livre e esclarecido (TCLE) que constava na página principal do link disponibilizado o 
questionário, caso concordassem com o seu conteúdo, marcavam a opção "sim", concordando com a participação na pesquisa. Este termo informou aos sujeitos sobre a ausência de custos e desconfortos para a sua integridade física e moral, assim como a possibilidade de ter suas informações retiradas do estudo no momento em que desejar, sem que fossem, de qualquer forma, penalizados por isso.

Em hipótese alguma, os dados pessoais dos sujeitos participantes da pesquisa foram divulgados, apenas os dados relativos aos resultados da avaliação foram materiais de análise, de estudo e publicação em revistas científicas.

\section{Resultados e Discussão}

A partir da análise dos dados coletados através do questionário, foram identificados três núcleos do sentido que possibilitaram compreender a concepção do lazer para os adultos, as mudanças de percepção ocorridas dentro dessa fase do desenvolvimento, bem como a função que o lazer exerce na vida desses indivíduos, que são: compreensões de lazer: "tempo e atitude"; transformações nas atividades de lazer: tecnologia versus estar com a família; "produtos" de lazer.

\section{Caracterização dos participantes}

Participaram deste estudo 21 adultos com idade entre 25 e 38 anos. A tabela 1 permite uma melhor visualização dos dados sociodemográficos dos participantes da pesquisa.

Tabela 1: Dados sociodemográficos dos participantes da pesquisa.

\begin{tabular}{|c|c|c|c|c|c|c|c|}
\hline Participante & Idade & Gênero & Cidade & $\begin{array}{l}\text { Raça/ } \\
\text { Etnia }\end{array}$ & $\begin{array}{l}\text { Grau de } \\
\text { escolaridade }\end{array}$ & Profissão & $\begin{array}{l}\text { CH semanal } \\
\text { de trabalho/ } \\
\text { Estudo }\end{array}$ \\
\hline
\end{tabular}




\begin{tabular}{|c|c|c|c|c|c|c|c|}
\hline $\mathrm{P} 1$ & 25 & Masculino & $\begin{array}{l}\text { João } \\
\text { Pessoa - } \\
\text { PB }\end{array}$ & Pardo & $\begin{array}{l}\text { Superior } \\
\text { incompleto }\end{array}$ & Estudante & $40 \mathrm{~h}$ \\
\hline $\mathrm{P} 2$ & 25 & Feminino & $\begin{array}{l}\text { Santa } \\
\text { Maria - RS }\end{array}$ & Branca & $\begin{array}{l}\text { Superior } \\
\text { completo }\end{array}$ & $\begin{array}{l}\text { Terapeuta } \\
\text { Ocupacional }\end{array}$ & $30 \mathrm{~h}$ \\
\hline P3 & 25 & $\begin{array}{l}\text { Nao } \\
\text { declarado }\end{array}$ & $\begin{array}{l}\text { São Carlos- } \\
\text { SP }\end{array}$ & Negra & $\begin{array}{l}\text { Superior } \\
\text { completo }\end{array}$ & $\begin{array}{l}\text { Terapeuta } \\
\text { Ocupacional }\end{array}$ & $40 \mathrm{~h}$ \\
\hline P4 & 26 & Feminino & $\begin{array}{l}\text { São Carlos } \\
- \text { SP }\end{array}$ & Parda & Pós-graduada & Estudante & $50 \mathrm{~h}$ \\
\hline P5 & 27 & Masculino & $\begin{array}{l}\text { João } \\
\text { Pessoa - } \\
\text { PB }\end{array}$ & Branco & Superior & Tradutor & $60 \mathrm{~h}$ \\
\hline P6 & 28 & Feminino & $\begin{array}{l}\text { Bayeux - } \\
\text { PB }\end{array}$ & Parda & Ensino médio & Microempresária & $10 \mathrm{~h}$ \\
\hline P7 & 28 & Feminino & $\begin{array}{l}\text { São Paulo } \\
- \text { SP }\end{array}$ & Branca & $\begin{array}{l}\text { Pós-graduação } \\
\text { completa. } \\
\text { Mestrado em } \\
\text { andamento. }\end{array}$ & $\begin{array}{l}\text { Terapeuta } \\
\text { Ocupacional }\end{array}$ & $\begin{array}{l}\text { Trabalho: } \\
30 \mathrm{hs} \\
\text { semanais; } \\
\text { Estudo } \\
20 \mathrm{hs} \\
\text { semanais. }\end{array}$ \\
\hline P8 & 28 & Feminino & $\begin{array}{l}\text { João } \\
\text { Pessoa - } \\
\text { PB }\end{array}$ & Negra & $\begin{array}{l}\text { Superior } \\
\text { Cursando }\end{array}$ & Professora & $10 \mathrm{~h}$ \\
\hline P9 & 28 & Feminino & $\begin{array}{l}\text { São Carlos } \\
\text { SP }\end{array}$ & Branca & $\begin{array}{l}\text { Mestrado em } \\
\text { andamento }\end{array}$ & $\begin{array}{l}\text { Terapeuta } \\
\text { ocupacional/ } \\
\text { Estudante }\end{array}$ & $36 \mathrm{~h}$ \\
\hline Participante & Idade & Gênero & Cidade & $\begin{array}{l}\text { Raça/ } \\
\text { Etnia }\end{array}$ & $\begin{array}{l}\text { Grau de } \\
\text { escolaridade }\end{array}$ & Profissão & $\begin{array}{l}\text { CH } \\
\text { semanal de } \\
\text { trabalho/ } \\
\text { Estudo } \\
\end{array}$ \\
\hline $\mathrm{P} 10$ & 29 & Masculino & $\begin{array}{l}\text { Bayeux - } \\
\text { PB }\end{array}$ & Parda & Superior & $\begin{array}{l}\text { Auxiliar } \\
\text { administrativo }\end{array}$ & $50 \mathrm{~h}$ \\
\hline P11 & 30 & Feminino & $\begin{array}{l}\text { João } \\
\text { Pessoa -PB }\end{array}$ & Branca & $\begin{array}{l}\text { Superior } \\
\text { completo }\end{array}$ & $\begin{array}{l}\text { Professora de } \\
\text { francês }\end{array}$ & $35 \mathrm{~h}$ \\
\hline $\mathrm{P} 12$ & 30 & Feminino & $\begin{array}{l}\text { Marituba - } \\
\text { PA }\end{array}$ & Parda & Superior & $\begin{array}{l}\text { Terapeuta } \\
\text { ocupacional }\end{array}$ & $30 \mathrm{~h}$ \\
\hline P13 & 31 & Feminino & $\begin{array}{l}\text { Bayeux - } \\
\text { PB }\end{array}$ & Branca & Superior & $\begin{array}{l}\text { Assessora } \\
\text { jurídica }\end{array}$ & $12 \mathrm{~h}$ \\
\hline P14 & 31 & Masculino & $\begin{array}{l}\text { Bayeux - } \\
\text { PB }\end{array}$ & Pardo & $\begin{array}{l}\text { Superior } \\
\text { completo }\end{array}$ & Professor & $40 \mathrm{~h}$ \\
\hline P15 & 31 & Feminino & $\begin{array}{l}\text { João } \\
\text { Pessoa - } \\
\text { PB }\end{array}$ & Parda & $\begin{array}{l}3 \text { grau } \\
\text { completo }\end{array}$ & Videofonista & $6 \mathrm{~h}$ \\
\hline P16 & 34 & Feminino & $\begin{array}{l}\text { Campina } \\
\text { Grande - } \\
\text { PB }\end{array}$ & Branca & $\begin{array}{l}\text { Superior } \\
\text { incompleto }\end{array}$ & $\begin{array}{l}\text { Tradutora/ } \\
\text { Intérprete de } \\
\text { Libras }\end{array}$ & $40 \mathrm{~h}$ \\
\hline P17 & 35 & Masculino & Caicó - RN & Branca & Superior & Empresário & $48 \mathrm{~h}$ \\
\hline P18 & 36 & Feminino & $\begin{array}{l}\text { João } \\
\text { Pessoa- PB }\end{array}$ & Parda & $\begin{array}{l}\text { Ensino superior } \\
\text { completo }\end{array}$ & Professora & $\begin{array}{l}40 \text { aulas por } \\
\text { semana }\end{array}$ \\
\hline
\end{tabular}




$\begin{array}{ccclllll}\text { P19 } & 36 & \text { Feminino } & \begin{array}{l}\text { João } \\ \text { Pessoa }- \\ \text { PB }\end{array} & \text { Branca } & \text { Mestrado } & \text { Jornalista } & 45 \mathrm{~h} \\ \text { P20 } & 37 & \text { Feminino } & \begin{array}{l}\text { São Carlos } \\ - \text { SP }\end{array} & \text { Branca } & \text { Mestre } & \begin{array}{l}\text { Terapeuta } \\ \text { Ocupacional }\end{array} & \begin{array}{l}30 \text { horas } \\ \text { aproximada } \\ \text { mente }\end{array} \\ \text { P21 } & 38 & \text { Feminino } & \begin{array}{l}\text { Bayeux }- \\ \text { PB }\end{array} & \text { Branca } & \begin{array}{l}\text { Ensino Médio } \\ \text { Completo }\end{array} & \text { Comerciante } & \end{array}$

Fonte: Dados coletados pela autora (2018).

Os participantes são em sua maioria do gênero feminino, sendo 16 destes, 5 do gênero masculino e 1 não declarado. Com relação à raça/etnia, 12 destes se consideram brancos, 8 pardos, 2 negros.

O estudo conseguiu alcançar 3 regiões do país, de 5 estados do Brasil, sendo 7 participantes de João Pessoa-PB, 5 de Bayeux-PB, 4 de São Carlos-SP, 1 de Caicó RN, 1 de Campina Grande-PB, 1 de Marituba - PA, 1 de São Paulo-SP, e 1 de Santa Maria-RS.

O grau de escolaridade dos participantes varia de Ensino Médio completo (2), Superior Incompleto/cursando (3), Superior Completo (11), Pós-graduação (5). As profissões se diversificam em Comerciante (1), Terapeutas Ocupacionais (6), Jornalista (1), Professores (4), Empresário/Microempresário (2), Tradutores (2), Videofonista (1), Assessora Jurídica (1), Auxiliar administrativo (1), Estudantes (2).

Quando analisamos tais dados, é possível refletir o conceito de Capital Cultural instituído por Pierre Bourdieu (2010a; 2010b), que trata a cultura como um capital equivalente até mesmo ao econômico - ou seja, a educação, o acesso a livros e outros materiais semelhantes têm grande valor na divisão de classes. $\mathrm{O}$ autor discute ainda sobre a desigualdade simbólica e material que levam às hierarquizações sociais.

O capital cultural pode ser entendido como um conjunto de valores e disposições constituídos pelos diversos agentes na exposição à educação familiar e escolar, o que pode implicar numa atitude positiva e de reconhecimento frente às práticas educativas e culturais (ARACRI, 2015 p. 63). 
Este conceito implica diretamente na caracterização de lazer, pois, quando se tem acesso ao capital cultural, a tendência é que a concepção e a importância atribuídas ao lazer sejam diferenciadas daquele que não tem; estes baseiam seu entendimento, muitas vezes, em uma visão reducionista.

Assim, diante do perfil sociodemográfico dos participantes e de suas escolaridades, podemos inferir que há um capital cultural acumulado caracterizando este grupo. Sendo assim, a análise dos dados foi feita com base neste recorte, não podendo ser generalizada para todas as possibilidades de ser adulto na sociedade brasileira.

A compreensão do que é lazer pelas pessoas, muitas vezes, não significa que elas estão colocando-a em prática de maneira efetiva. O cotidiano é composto por um conjunto de atividades - autocuidado, educação, gerenciamento pessoal, trabalho, lazer, entre outras. Algumas tomam um maior tempo dentro de nossa rotina por serem consideradas pelos indivíduos como obrigatórias e/ou urgentes. O trabalho e o estudo visto como caminho para alcançar o trabalho mais qualificado - tomam grande parte desse tempo. Como aborda Dumazedier em suas obras (2001, 1979), vivemos na sociedade do trabalho, o que torna difícil dissociá-lo do lazer.

Diante disso, o Gráfico 1 apresenta o tempo gasto no trabalho e no lazer semanalmente dos 21 participantes da pesquisa, de modo a fazer um paralelo entre Trabalho-Lazer. 


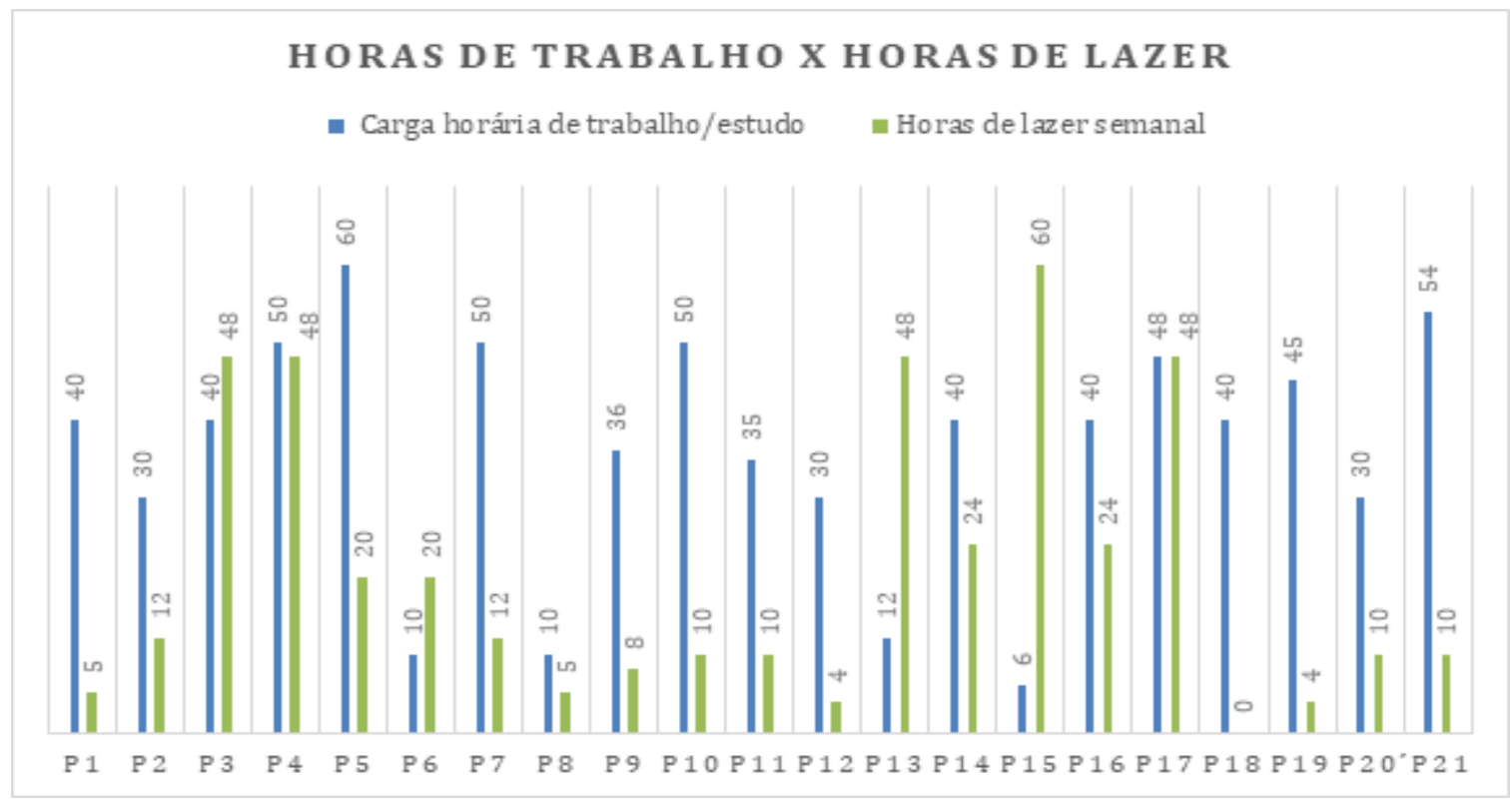

Fonte: Dados coletados pela autora (2018).

Através da análise do Gráfico 1, é possível refletir acerca da centralidade do trabalho na vida adulta e das horas destinadas ao lazer. Dos 21 participantes da pesquisa, 11 atribuem menos da metade das horas de trabalho ao lazer semanalmente, enquanto apenas 4 reservam mais horas ao lazer do que ao trabalho.

Esses dados refletem o que é esperado pela sociedade, uma maior ênfase ao trabalho, ao qual o homem moderno acaba por ficar preso devido à sua centralidade e supervalorização. Zarotis; Katsagolis e Mitrotasios (2007) consideram que muitos desses indivíduos acabam por buscar no trabalho o significado para a própria vida (SILVA; SILVA, 2011).

Segundo Almeida e Gutierrez (2011), diante das circunstâncias atuais do mundo contemporâneo o lazer acaba por assumir um caráter complexo por envolver: "a) sistematização dos tempos (separação do mundo das obrigações e do divertimento); e b) desencantamento do mundo (racionalização das formas de vida).” (p. 139)

Diante disso, foi possível perceber a partir do dados coletados a influência que o trabalho e a cultura exercem na forma em que o indivíduo vivencia e enxerga o lazer, de 
modo que, as aquisições culturais ao longo da vida dos indivíduos o faz compreender, geralmente, o lazer como algo fundamental para sua vida, porém o cotidiano e a rotina cada vez mais encharcada de atividades vistas como obrigatórias faz com que este mesmo indivíduo adie cada vez mais as atividades prazerosas para horas livres, sendo cada vez mais escassas, ou até mesmo uma confusão entre o lazer e o trabalho - por viver tão imerso a este- confundindo assim satisfação profissional com pessoal.

\section{Compreensões de Lazer: "Tempo e Atitude"}

Quanto à concepção de lazer, os participantes da pesquisa o associaram a satisfação pessoal, descanso, bem-estar, relaxamento, entre outras possibilidades que o tiram de sua rotina convencional de obrigações.

Aquilo que me traz prazer. Que não é algo obrigatório, como, por exemplo um emprego (P1).

Atividades de descanso, distração, que podem ou não estar incluídas na rotina semanal $(\mathrm{P} 3)$.

Atividades que estão fora do horário de estudo/trabalho e trazem satisfação pessoal (P4).

Exercício de atividades prazerosas, momento de folga, entretenimento, recreação, distração. Ações que são realizadas no tempo livre, ou seja, fora das obrigações profissionais e/ou educacionais (P19).

Assim como considera Marcellino (2006), “a realização de qualquer atividade de lazer envolve a satisfação de aspirações dos seus praticantes.” (p.17) Desse modo, na sociedade do trabalho em que vivemos, devido ao ritmo acelerado, é comum buscar no lazer atividades que contemplem o tempo livre e a satisfação pessoal, o descanso.

Há ainda quem visualize o lazer, não somente como uma prática individual, mas “algo que deve fazer parte da vida de todos, até porque é um direito." P18. Essa concepção deixa subentendida que o lazer ainda não é materializado para todos, mesmo 
estando previsto na Constituição Federal (1988) como um exercício social de acesso de todos.

De fato, as atividades e ações na sociedade voltadas para a garantia desse direito são escassas. No entanto Menegaldo; Basei e Bendrath (2017) descrevem como um dos motivos, o despreparo dos gestores para a falta de investimento prático no ramo do lazer,

Este entendimento reducionista dos gestores sobre o lazer consubstancialmente torna as ações restritas, pois como os mesmos não conhecem todos os conteúdos ou até mesmo os que não têm conhecimento sobre o assunto, não possuem dimensão e amplitude das possibilidades, logo, não investem neste segmento como política pública (p. 271).

Quanto à importância atribuída pelos indivíduos ao lazer, os sujeitos da pesquisa consideram de muita importância e destacam o quanto ele é associado com a saúde mental, a qualidade de vida, e como uma válvula de escape do trabalho.

[...] fundamental para o equilíbrio e saúde mental (P4).

Muito importante para a manutenção da saúde mental, inclusive (P7).

O lazer é de suma importância para o corpo e a mente, ajuda a melhorar no desempenho de atividades do dia-a-dia (P11).

Melhora da qualidade de vida (esfera física, emocional) fuga da rotina, proximidade com os familiares, principalmente do filho que requer atenção. Válvula de escape para os dias de estresse (P12).

O lazer é vital para a manutenção da nossa saúde física e mental. Sem ele adoecemos (P19).

Essas concepções apresentadas acerca da importância do lazer podem ser facilmente associadas às ideias que Dumazedier (2004) apresenta sobre as funções do lazer na vida dos sujeitos: o descanso, de modo que o lazer funciona como reparador dos desgastes físicos, mentais e emocionais provocados pelo ritmo cotidiano 
massacrante, sobretudo, do trabalho; o divertimento, que atua como agente para higiene mental; e o desenvolvimento pessoal.

Em contraposição ao trabalho, o lazer quase sempre é visto como uma válvula de escape, uma vez que possibilita ao trabalhador suportar a disciplina e a regra, compensar a insatisfação e alienação provocada pela mecanização das ações profissionais, recuperar as forças físicas, aliviar o estresse, sempre em busca da paz e da harmonia social. Sua perspectiva revolucionária é acentuada diante das características de participação, criticidade, criatividade, autonomia, capazes de provocar mudanças na ordem social, na coletividade e também na dimensão individual. O lazer é instrumento de transformação da sociedade, promotor do ser humano em si mesmo, é saúde e qualidade de vida (MASSON; BERTOLO; PINHEIRO, 2015 n.p).

Trombly (2005) já dizia “o lazer é intrinsecamente motivado e autorregulado pelo indivíduo e, dessa forma, contribui para que a pessoa se sinta no controle de sua própria vida" (p.489)

Assim, é possível observar que as concepções de lazer que os participantes têm, são associadas diretamente ao tempo livre, em que não está trabalhando ou estudando, o que corrobora com a definição de Dumazedier (1979), considerando o aspecto pessoal, desinteressado, hedonístico e liberatório. Os participantes também atribuíram um alto grau de importância do lazer, ressaltando seu benefício para a saúde mental.

Deste modo, foi possível verificar que os sujeitos compreendem como lazer aquilo que the proporciona bem estar e satisfação pessoal, comumente associado ao descanso do trabalho e/ou do estudo, bem como, o associam como um direito, que deveria ser garantido a todos, mesmo que ainda tenha pouco investimento público na implementação dos espaços de lazeres. De modo que, a partir desta compreensão, eles conseguem perceber a importância que o lazer os proporcionam, e o associam ao equilíbrio e manutenção da saúde mental e qualidade de vida. 


\section{Transformações nas Atividades de Lazer: Tecnologia Versus estar com a Família}

Levando em consideração o pressuposto da pesquisa de que concepções de lazer se transformam de acordo com a faixa etária, foi possível verificar que há um movimento de mudança da percepção das atividades consideradas por esses indivíduos como sendo de lazer.

É perceptível que os adultos na faixa etária dos 25 aos 29 anos (que nasceram em 1993 e 1989) tendem a considerar mais as atividades de lazer como sendo ir ao cinema, sair com os amigos, usar a internet, ou assistir séries.

Segundo Almeida e Gutierrez (2011), a escolha de atividades desse tipo como sendo de lazer é justificada através do fenômeno da globalização, que ampliou as opções e acesso a essas atividades, com grande influência do Mercado, que investiu massivamente em atividades lucrativas transformando assim o movimento de escolha de lazeres.

Com a democratização e a globalização a possibilidade de interação é ampliada, influindo no lazer, já que ele surge da necessidade de socialização, divertimento e busca de prazer com seus pares. A possibilidade de encontros em bares e restaurantes; o aumento dos locais para divertimento, como parques temáticos; o crescimento do turismo e de formas alternativas de se viajar; os locais para prática de atividade física que aumentaram significativamente nos últimos anos, como as academias e parques; [...] o uso da Internet como forma de lazer; os jogos eletrônicos; enfim as práticas de lazer têm no período democrático a sua forma mais ampla e irrestrita de atividade (p.148).

O autor ainda problematiza o movimento de mudança das tendências de lazer, na era atual, o qual as pessoas, principalmente os mais jovens, cada vez mais, optam pelos meios digitais como atividade de lazer.

Trata-se, da diferença entre os meios técnicos da produção artística e do conteúdo do produto cultural em si. [...] Será que viveremos em um mundo onde cientistas desenvolverão experiências com a utilização de sensores para reproduzir integralmente vivências humanas? [...] Esta poderá ser a grande tendência do lazer? A busca por emoções virtuais, sem sair de casa fechado no mundo hedonista micro-estruturado? A busca do prazer se dará mais rapidamente com a possibilidade de 
sensações e simulações bem próximas ou idênticas à realidade? [...] a Internet nasceu na democracia, tendo grande circulação e importância cada vez maior no mundo atual. Primeiramente pela velocidade e segundo pela quantidade de informações (ALMEIDA; GUTIERREZ, 2011, p.149).

No entanto, ao observar as respostas atribuídas à mesma questão pelos adultos da faixa etária dos 30 aos 38 anos (nascidos nos anos de 1988 a 1980), é possível verificar uma sutil mudança em seus discursos. Eles citam espetáculos teatrais, saídas com familiares, brincadeiras com filhos, leitura de livros e há até mesmo quem considere o trabalho como sendo atividade de lazer.

Segundo Sousa (2008), em seu estudo foi possível concluir que aos 30 anos a maioria dos sujeitos $(80 \%)$ já viveram a primeira experiência profissional, a primeira conjugalidade e já haviam constituído família. Cabe ressaltar que, mesmo a adultez não seguindo um padrão linear de desenvolvimento, já que este é advindo a partir do processo de vivências sociais e culturais, há um padrão representativo que os indivíduos consideram-se adultos quando tem uma família e um trabalho, de modo que 79,4\% dos sujeitos de sua pesquisa consideram importante ou muito importante "estar em família" para se "ser adulto" (SOUSA, 2008).

Muitas pessoas encontram no rito familiar o prazer máximo de suas existências. Os pequenos gestos do cotidiano, as manifestações afetivas entre os parceiros e com os filhos são capazes de preencher para eles as necessidades de exercício físico, de criatividade manual, de sonho, de informação, de sociabilidade (CAMARGO, 1989 n.p).

Quando questionados acerca das atividades de lazer exercidas no cotidiano, os participantes da faixa etária mais jovem destacaram atividades como assistir filmes, séries, e jogar videogame com mais frequência que os da faixa etária mais velha, que preferem se reunir com a família, ler, e fazer bricolage.

É interessante refletir acerca das fases da vida adulta e subcategorias apresentadas por Mosquera; Stobaus (1982), e anteriormente apresentadas, as quais 
referem-se como adulto jovem pleno dos 25 aos 35 anos, e o adulto jovem final, dos 35 aos 40 anos, especificando que cada subdivisão dessa apresenta características específicas. Porém, quando analisados os resultados aqui apresentados, foi possível visualizar que as mudanças mais perceptíveis nos discursos dos participantes ocorriam, principalmente, na mudança de faixa etária dos 20 para os 30 anos.

Tal fato pode ser caracterizado por um dos momentos de transição do jovem adulto, que segundo Agudo (2008), acontece na transição da fase Teen para a fase em que o adulto reconhece-se como tal através da aquisição de papeis sociais, disseminados culturalmente como sendo "adultos". Tal autor baseia-se na ideia de que uma “esmagadora maioria dos adultos na faixa dos 30 anos, estão casados, tornaram-se pais e não estão matriculados em escolas" (p.15). No entanto, cabe ressaltar que essas vivências também representam um recorte socioeconômico e cultural, pois para determinados sujeitos e coletivos, os papeis sociais podem ser outros.

Contudo, no discurso de ambas as faixas etárias, também identificamos atividades que são comumente consideradas e exercidas como lazer: viajar, praticar esportes, atividades físicas, frequentar praias e piscinas. Estas atividades elencadas como em comum são aquelas advindas da atual sociedade do consumo a qual estamos alocados. De acordo com Taschner (2000) "a maioria das atividades de lazer é, hoje, mediada pelo mercado ir ao cinema, viajar a turismo, ver TV e conversar pela Internet são alguns exemplos.” (p.39)

Dessa forma, percebe-se que a partir do que Bourdieu (2010a) nomeia como capital cultural, a compreensão das atividades de lazer e as práticas exercidas pelos participantes, representam uma camada da sociedade que possui acessos privilegiados à cultura. 


\section{"Produtos de Lazer"}

Acerca da compreensão do que é mais valorizado pela sociedade enquanto atividades de lazer, os participantes da pesquisa associaram a viagens, a esportes, atividades realizadas fora de casa (passeios, idas a restaurantes e bares), e o uso de redes sociais.

Segundo Taschner (2000) "o lazer tem sido abordado primariamente como parte da cultura contemporânea do consumo." (p. 39). Muito do que é percebido enquanto lazer pelos indivíduos parte da ideia do consumo, que nada mais é que "a aquisição, a posse e/ou o uso (incluindo a exibição) de bens de serviço". (p.39)

É nítida a concepção que estes indivíduos têm acerca do que é considerado como atividades de lazer são atividades de consumo. Suas respostas trazem a tona essa concepção:

Atividades que exijam investimento financeiro (P. 20).

Só se tem lazer quando tem dinheiro (P.13).

"Produtos" que o capitalismo vende como lazer (P.21).

É através dessa imagem vendida, principalmente nos canais de comunicação de massa sobre lazer que é criado o imaginário social que só consegue ter lazer quem tem dinheiro para comprar. Diante disso, Oliveira (2004a) discute acerca do poder da influência que os meios de comunicação exercem sobre o lazer difundido em uma sociedade consumista:

Nas últimas décadas, a indústria do entretenimento - sinônimo de lazer para muitos - seduz o consumidor, sugerindo-lhe as sessões adequadas para sua satisfação. Vê-se então a idéia reducionista do lazer sendo alimentada e veiculada pelos meios de comunicação de massa sendo que mal interpretada, a idéia é vendida, na maioria dos casos, como atividade física/esportiva, artística/cultural, recreativa, ao ar livre e/ou em espaços intencionalmente construídos para tais fins, com um grande número de pessoas bonitas e felizes, e uma parafernália de 
produtos que referenciam, socialmente, a qualidade de tal lazer ( $\mathrm{p}$. 20).

Assim, a relação de consumo e lazer é acirrada com a publicidade, que nos bombardeia com propagandas e anúncios, o que é potencializado com o fenômeno do mundo virtual. Este lazer estaria justamente associado ao consumo realizado no tempo ocioso (OLIVEIRA; SANGY, 2015).

Quando questionados acerca dos fatores que implicam/limitam o acesso ao lazer, 11 dos participantes do estudo atribuiu a falta de recurso financeiro. $\mathrm{O}$ que nos leva a refletir o que as pessoas estão ainda a conceber como sendo lazer. De fato, as atividades atribuídas como sendo de grande valor hoje são as vendidas pela cultura do consumo, porém, como refere-se Schwartz et al.(2005),

[...] considerar o lazer apenas por esta ótica pode forjar as experiências, conduzindo-as a uma massificação, em que os indivíduos envolvidos precisam estar in, para poderem ter a sensação de pertencimento, tão necessária à satisfação das necessidades humanas (n.p).

O lazer, como já referido anteriormente, pode contemplar diversas áreas, e nem todas essas áreas são compostas apenas de atividades que demandam recursos financeiros a serem investidos. Apesar disso, há um crivo na concepção na qual os participantes apresentam inicialmente como o que consideram como atividades de lazer, para posteriormente refletir sobre as limitações que eles têm para acessar o lazer.

Nesse sentido, observamos que os recursos viabilizadores do exercício das atividades de lazer, sobretudo no que concerne aos fatores financeiros, são incorporados às concepções de lazer dos sujeitos da pesquisa. Isso permite que enxerguemos relações intrínsecas entre as noções em geral difundidas pela sociedade e as constitutivas das subjetividades dos indivíduos em questão. 


\section{Considerações Finais}

Com base nos resultados deste estudo, foi possível visualizar que, dentre a população pesquisada, a faixa etária dos adultos de 25 a 38 anos concebem como lazer aquilo que lhes proporciona satisfação pessoal e descanso, enquanto livres de suas obrigações, que ainda estão muito associadas ao trabalho.

Destarte, consideram que a prática do lazer é de grande importância em suas vidas, associando-o a questões positivas de manutenção da saúde mental, e aquisição de qualidade de vida. Afirmando-o enquanto direito de todos, porém reconhecem que nem sempre todos vão acessá-lo.

As atividades consideradas como de lazer ainda estão muito associadas ao consumo, de modo que reflete até mesmo na percepção desses sujeitos acerca do que limita seu lazer, já que a grande maioria associa à falta de recurso financeiro. Em contrapartida, criticam que a sociedade só valoriza o que parte da ordem do ter, do exibir, do comprar.

Foi verificado também que, mesmo que a literatura considere como adulto jovem pleno dos 25 aos 35 anos, e adulto jovem final dos 35 aos 40 anos, as mudanças mais perceptíveis no que é entendido e executado como atividade de lazer ocorreram nas faixas etárias dos 25 aos 29 anos e dos 30 aos 38 anos, havendo influência do contexto histórico, econômico e cultural que esses indivíduos vivenciaram, ou seja, uma época a qual estava se efetivando uma nova era globalizada.

Cabe ressaltar que esse estudo apresentou um recorte da população adulta, trazendo a tona elementos críticos e reflexivos dos participantes acerca do que é entendido e efetivado como lazer pelos participantes da pesquisa e suas relações com o trabalho e consumo. 
Embora julguemos ter alcançado os objetivos propostos, é válido ressaltar algumas limitações identificadas no estudo. A escolha da técnica "bola de neve" para seleção dos participantes impossibilitou uma maior abrangência das classes socioeconômicas, de modo que o estudo acabou centrado em apenas um grupo - os que têm ensino médio completo, superior e pós-graduação - (grupo com Capital Cultural privilegiado), não contemplando as diversidades socioculturais das vivências de lazer na fase adulta.

Os resultados desta pesquisa, constituem portanto, apenas algumas provocações a comunidade acadêmica, aos profissionais que atuam com o lazer e aos leitores que, no ordinário de suas vivencias cotidianas, estabelecem diferentes relações com esse bem essencial. Assim, abre-se margem para outros estudos abordem essa temática sob outras perspectivas, inclusive no que concerne a outros recortes socioeconômicos e culturais, bem como, outras faixas etárias da vida adulta, já que, a partir de nosso levantamento bibliográfico, constatamos um maior direcionamento das análises sobre lazer ao público infantil e idoso. No terreno intersubjetivo de divergentes e convergentes concepções sobre o tema, as reflexões teóricas traçam um caminho para organizar ideias e pensamentos sem, entretanto, firmar verdades incontestáveis. Através disso, manifestase o atributo essencial do fazer científico, a fluidez da construção do conhecimento.

\section{REFERÊNCIAS}

AGUDO, Viviana Raquel Cascalheira. A transição para a idade adulta e os seus marcos: que efeito na sintomatologia depressiva? 2008. 66 f. Dissertação (Mestrado) Curso de Psicologia, Universidade de Lisboa, Lisboa, 2008. Disponível em: http://repositorio.ul.pt/bitstream/10451/3086/2/ulfp037654_tm_tese.pdf. Acesso em: 15 set. 2018. 
ALBUQUERQUE, E. M. Avaliação da técnica de amostragem "Respondent-driven Sampling" na estimação de prevalências de Doenças Transmissíveis em populações organizadas em redes complexas. Escola Nacional de Saúde Pública Sérgio Arouca ENSP; Rio de Janeiro: Ministério da Saúde - Fiocruz, 2009. Dissertação de Mestrado, 99p.

ALENCAR, T.O.S.; NASCIMENTO, M.A.A; ALENCAR, B.R. Hermenêutica Dialética: Uma experiência enquanto método de análise na pesquisa sobre o acesso do usuário à assistência farmacêutica. Revista Brasileira em Promoção da Saúde, Fortaleza, v. 25, n. 2, p.243-250, abr. 2012.

ALMEIDA, M.A.B.; GUTIERREZ, G.L. Análise do desenvolvimento das práticas urbanas de lazer relacionadas a produção cultural no período nacionaldesenvolvimentista à globalização. Rev. Bras. Educ. Fís. Esporte, São Paulo, v. 25, n. 1, p.137-152, jan. 2011. Disponível em: https://www.scielo.br/pdf/rbefe/v25n1/13.pdf . Acesso em: 02 out. 2018.

ALVES, C; MARCELLINO, N.C. O profissional de Educação Física como Animador Sociocultural atuando nos clubes da cidade de Americana-SP: Contribuições nas relações entre o lazer e a idade adulta. Licere, Belo Horizonte, v. 11, n. 1, p.1-19, abr. 2008. /Disponível em: https://seer.ufmg.br/index.php/licere/article/view/636/519 Acesso em: 11 ago. 2018.

ARACRI, E.M.R.P. Professores no museu da Geodiversidade: O Capital Cultural nas percepções e expectativas da relação museu x escola. 2015. $160 \mathrm{f}$. Tese (Doutorado) - Curso de Educação, Pontifícia Universidade Católica do Rio de Janeiro - Puc-rio, Rio de Janeiro, 2013. Disponível em: https://www.maxwell.vrac.pucrio.br/Busca_etds.php?strSecao=resultado\&nrSeq=23930@1\&msg=28\# . Acesso em: 26 ago. 2018.

ARAÚJO, C. M. Significações sobre adolescência e desenvolvimento em um projeto social educativo.2008. 113 f. Dissertação (Mestrado) - Curso de Psicologia, Universidade de Brasília, Brasília, 2008. Disponível em: http://repositorio.unb.br/handle/10482/5715 . Acesso em: 15 jun. 2019.

BARCELOS, B.S. A relação sociedade $\mathbf{X}$ tempo $\mathbf{X}$ trabalho: como o uso do tempo e a dedicação ao trabalho podem influenciar a vida pessoal e social do ser humano contemporâneo. 2009. 1 f. Monografia (Especialização) - Curso de Produção Cultural, Universidade Federal Fluminense, Niterói, 2009. Disponível em: https://www.administradores.com.br/artigos/economia-e-financas/a-relacaosociedade-X-tempo-x-trabalho-como-o-uso-do-tempo-e-a-dedicacao-ao-trabalhopodem-influenciar-a-vida-pessoal-e-social-do-ser-humano-contemporaneo/36389/ Acesso em: 10 ago. 2018.

BARROS, D. D; ALMEIDA, M.C; VECCHIA, T.C. Terapia ocupacional social: diversidade, cultura e saber técnico. Rev. Ter. Ocup. Univ. São Paulo, São Paulo, v. 18, n. 3, p.128-134, set. 2007. Disponível em: http://www.cadernosdeterapiaocupacional.ufscar.br/index.php/cadernos/article/viewFi le/991/795 . Acesso em: 30 ago. 2018. 
BIERNACKI, P.; WALDORF, D. Snowball Sampling: Problems and techniques of Chain Referral Sampling. Sociological Methods \& Research, n. 2, Nov. p. 141-163, 1981.

BOURDIEU, P. A escola conservadora: as desigualdades frente à escola e à cultura. In: NOGUEIRA, M. A. e A. CATANI (Orgs). Escritos de Educação. Petrópolis: Vozes, 2010a, p. 39-64.

. Os três estados do Capital Cultural. In: NOGUEIRA. M. A.; CATANI, A. (organizadores). Escritos de Educação. Petrópolis: Editora Vozes, 2010b. p. 71-80

BOUTINET, J.P. A imaturidade da vida adulta. Porto: Rés, 2000.

BRASIL. Constituição (1988). Constituição da República Federativa do Brasil. São Paulo: Saraiva, 2003.

CAMARGO, L.O.L. O que é lazer. São Paulo: Editora Brasiliense S.A, 1989. Disponível https://books.google.com.br/books?id=KGkvDwAAQBAJ\&lpg=PT5\&ots=2LCGDB K_z4\&dq=lazer\%20e\%20fam\%C3\%ADlia\&lr\&hl=pt$\mathrm{BR} \& \mathrm{pg}=\mathrm{PT} 43 \# \mathrm{v}=$ onepage $\& \mathrm{q}=$ Fam $\% \mathrm{C} 3 \%$ ADlia $\% 20$ pode $\% 20$ ser $\% 201$ lazer? $\& \mathrm{f}=$ false. Acesso em: 01 out. 2018.

CARNEIRO, V.T.; SAMPAIO, S.M.R. Adultez emergente: um fenômeno normativo? Revista Saúde e Ciência Online, v. 4, n.1, p. 32-40, 2015.

DUMAZEDIER, J. Lazer e cultura popular. São Paulo: Editora Perspectiva S.A., 2001.

Sociologia empírica do lazer. São Paulo: Perspectiva, 1979.

DUMAZEDIER, J. Sociologia empírica do lazer. 2. ed. São Paulo: Perspectiva, 2004.

GOMES, C. L. Verbete Lazer - Concepções. In: GOMES, Christianne L. (Org.).

Dicionário Crítico do Lazer. Belo Horizonte: Autêntica Editora, 2004. p.119-126.

LEVINSON, D. The Seasons of a Man's Life. New York: Albert A. Knopf, 1977.

LOPES, A.C.M. O Direito Social ao Lazer em Perspectiva Crítica: Desigualdades e democratização do Acesso. 2017. 197 f. Dissertação (Mestrado) - Curso de Direito, Pontifícia Universidade Católica do Rio de Janeiro, Rio de Janeiro, 2017. Disponível em: https://www.maxwell.vrac.puc-rio.br/31968/31968.PDF . Acesso em: 12 ago. 2018.

MARCELLINO, N. C. Lazer e cultura: algumas aproximações. In: MARCELLINO, N. C. (org.). Lazer e cultura. Campinas: Editora Alínea, 2007

MARCELLINO, N.C. Lazer e educação. Campinas: Papirus, 1987.

. Estudos do lazer: Uma introdução. Campinas: Autores associados, 2006. 
MARTINELLI, S.A. A importância de atividades de lazer na Terapia Ocupacional. Cadernos de Terapia Ocupacional da Ufscar, São Carlos, v. 19, n. 1, p.111-118, jan. 2011.

MASSON, L.F.F; BERTOLO, M.A; PINHEIRO, F.P. A vivência dos conteúdos culturais do lazer dos jovens de São José do Rio Preto. Revista Científica Unilago, São José do Rio Preto, n.p, jan. 2015. Disponível em: http://www.unilago.edu.br/revista/edicaoatual/Sumario/2015/downloads/1.pdf Acesso em: 09 set. 2018.

MENDONÇA, M.P.G. Processo de transição e percepção de adultez: análise diferencial dos marcadores identitários em jovens estudantes e trabalhadores. 2007. 172 f. Dissertação (Mestrado) - Curso de Psicologia Social, Universidade do Porto, Porto, 2007.2 Disponível em: https://www.researchgate.net/publication/37656531_Processo_de_transicao_e_percepc ao_de_adultez_analise_diferencial_dos_marcadores_identitarios_em_jovens_estudant es_e_trabalhadores. Acesso em: $1 \overline{0}$ out. 2018.

MENEGALDO, P.H.I; BASEI, A.P; BENDRATH, E.A. A Implementação de políticas públicas de lazer e suas relações com o Capital Cultural dos gestores municipais. Licere, Belo Horizonte, v. 20, n. 1, p.250-273, mar. 2017. Disponível em: https://seer.ufmg.br/index.php/licere/article/view/4437/3206 . Acesso em: 26 ago. 2018.

MINAYO, M.C. de S. O desafio do conhecimento: pesquisa qualitativa em saúde. São Paulo-Rio de Janeiro, HUCITEC-ABRASCO, 1992.

2001.

Pesquisa Social. Teoria, método e criatividade. 18. ed. Petrópolis: Vozes,

MOSQUERA, J.J.M; STOBÄUS, C.D. Vida Adulta: Visão Existencial e Subsídios para Teorização. Educação, Porto Alegre, n. 5, p. 94-112, 1982.

MOURA, R.M. A vida adulta: uma visão dinâmica. Portugal, 1999. Disponível em: http://members.tripod.com/RMoura/vidaadult.htm Acesso em 23 de jan. de 2018.

NASCIMENTO, T. C. M. O tempo livre e a produção da existência da ju-ventude do campo: um estudo com jovens estudantes do assentamento João Batista II - PA. 2017. 144 f. Dissertação (Mestrado) - Universidade Federal do Pará, Instituto de Ciências da Educação, Belém, 2017. Programa de Pós-Graduação em Educação. Disponível em: https://repositorio.ufpa.br/jspui/handle/2011/9314 Acesso em : 18 de jun. 2019

OLIVEIRA, C. B. Sobre lazer, tempo e trabalho na sociedade de consumo. Conexões: Educação Física, esporte e saúde, Campinas, v. 2, n. 1, p.20-34, jan. 2004a. Disponível em: https://periodicos.sbu.unicamp.br/ojs/index.php/conexoes/article/view/8637908/5599 . Acesso em: 09 out. 2018. 
OLIVEIRA, M.K. Ciclos de vida: algumas questões sobre a psicologia do adulto. Educação e Pesquisa, São Paulo, v. 30, n. 2, p. 211-229, Aug. 2004b. Disponível em: http://www.scielo.br/scielo.php?script=sci_arttext\&pid=S1517-

97022004000200002\&lng=en\&nrm=iso . Acesso em: 31 mar. 2018.

OLIVEIRA, J.A.; SANGY, M. Sociedade e cultura de consumo: aspectos históricos, simbólicos e culturais do consumo moderno. Políticas e Saúde Coletiva - Belo Horizonte - v. 1. n 2, setembro, 2015.

PALACIOS, J. Introdução à psicologia evolutiva: história, conceitos básicos e metodologia. In: COLL, C.; PALACIOS, J.; MARCHESI, A. (Orgs.) Desenvolvimento psicológico e educação: psicologia evolutiva. Porto Alegre: Artes Médicas, 1995.

SANTOS, B. S; ANTUNES, D. D. Vida adulta, processos motivacionais e diversidade. Educação, Porto Alegre/rs, v. 61, n. 1, p.149-164, jan. 2007.

SCHWARTZ, G. M. et al. Mídia impressa, comunicação e a disseminação do lazer. Efdeportes.com/ Revista Digital, Buenos Aires, v. 10, n. 88, p.1-1, set. 2005. Disponível em: http://www.efdeportes.com/efd88/midia.htm . Acesso em: 01 out. 2018.

SILVA, E.A.P.C; SILVA, P.P.C. LAZER, TRABALHO E CONSUMO: POSSÍVEIS APROXIMAÇÕES. Licere, Belo Horizonte, v. 14, n. 3, p.1-22, set. 2011. Disponível em: https://seer.ufmg.br/index.php/licere/article/view/487/379 . Acesso em: 17 ago. 2018 .

SOUSA, F. O que é "ser adulto"? As práticas e representações sociais - A Sociologia do Adulto. In: CONGRESSO PORTUGUÊS DE SOCIOLOGIA, 6., 2008, Lisboa. Anais... Lisboa: Universidade Nova Lisboa, 2008. p. 1 - 21. Disponível em: http://historico.aps.pt/vicongresso/pdfs/395.pdf . Acesso em: 08 out. 2018.

SOUSA, F. O que é "ser adulto"? Porto: Memória Imaterial, 2010. 340 p.

TASCHNER, G. B. Lazer, cultura e consumo. Rae: Revista de Administração de Empresas, São Paulo, v. 40, n. 4, p.38-47, out. 2000. Disponível em: http://www.scielo.br/pdf/rae/v40n4/v40n4a04.pdf . Acesso em: 09 out. 2018.

TROMBLY, C. A.; RADOMSKI, M. V. Terapia Ocupacional para Disfunções Físicas. 5.ed. São Paulo: Santos Editora, 2005.

VINUTO, J. Amostragem em bola de neve na pesquisa qualitativa: Um debate em aberto. Temáticas, Campinas, v. 44, n. 22, p.203-220, ago. 2014.

ZAROTIS, G. F.; KATSAGOLIS, A.; MITROTASIOS, M. Free time and its alteration tendencies. Studies in Physical Culture \& Tourism, v. 14, n. 2, p. 179-184, 2007. 


\section{Endereço das Autoras:}

Iara Falleiros Braga

Avenida Monteiro da Franca, 661 - Manaíra

João Pessoa - PB - 58.038-320

Endereço Eletrônico: iarafalleiros@gmail.com

Andrêza Roberta Bezerra dos Santos

Rua Juscelino Kubistchek, 389 - Jardim Aeroporto

Bayeux - PB - 58.038-320

Endereço Eletrônico: andrezaroberta18@gmail.com 